\title{
A atuação socioeducativa e política do professor do campo e as repercussões de suas ações nas relações escolares e extraescolares
}

\author{
Field teacher's socio-educational and policy performance and the repercussions \\ of his actions on school and ex-school relations
}

\author{
Renata dos Santos Xavier Sales ${ }^{1}$ \\ Alcione Sousa de Meneses ${ }^{2}$
}

\begin{abstract}
RESUMO
Este estudo tem a finalidade de analisar a prática socioeducativa e política do professor do campo e as repercussões de suas ações nas relações escolares e extraescolares. O método de pesquisa utilizado foi o estudo de caso por meio de pesquisa qualitativa, tendo como lócus a escola rural multisseriada (atualmente escola multiano) Nossa Senhora da Conceição, localizada no km 135 Norte, em Medicilândia. Mesmo com todas as dificuldades de acesso, falta de infraestrutura adequada, dentre outros problemas típicos das escolas no meio rural, a experiência docente analisada conseguiu desenvolver um significativo envolvimento entre família e escola, professor e aluno. Observa-se ainda uma influência positiva dessas relações, a partir de uma espécie de fortalecimento mútuo entre escola/docente-famíliasestudantes nem sempre explícito no processo de ensino e aprendizagem e no ambiente da escola. Nisso reside a importância do protagonismo docente para o fortalecimento da Educação do Campo, mesmo em condições adversas ao ideal de educação escolar diferenciada.
\end{abstract}

Palavras-chaves: Protagonismo Docente; Atuação Sociopolítica; Dialogicidade.

\begin{abstract}
This study aims to analyze the socio-educational and political practice of rural teachers and the repercussions of their actions on school and extra-school relations. The research method used was a case study through qualitative research, having as locus the multiseriate rural school (currently multiannual school) Nossa Senhora da Conceição, located at km 135 North, in Medicilândia. Even with all the difficulties of access, lack of adequate infrastructure, among other typical problems of rural schools, the teaching experience analyzed managed to develop significant involvement between family and school, teacher and student. There is also a positive influence of these relationships, through a kind of mutual strengthening between school / teacher-families-students not always explicit in the teaching and learning process and in the school environment. Herein lies the importance of teacher leadership in strengthening rural education, even in conditions that are adverse to the ideal of differentiated school education.
\end{abstract}

Keywords: Teacher Protagonism; Sociopolitical Performance; Dialogicity.

\footnotetext{
${ }^{1}$ Professora Licenciada pelo curso de Educação do Campo- Linguagens e Códigos. Turma 01 de Altamira, e-mail: renatadossantosxavier10@hotmail.com.

${ }^{2}$ Pedagoga. Mestre em Ciências Sociais. Professora da UFPA-Faculdade de Etnodiversidade, Curso de Licenciatura Interdisciplinar em Educação do Campo, e-mail: alcione@ufpa.br.
} 


\section{Introdução}

Este artigo versa sobre a figura do professor da educação básica nas escolas do meio rural, especialmente, a atuação socioeducativa e política de docentes em escolas que tem mais dificuldades de acesso à cidade, infraestrutura, apoio pedagógico entre outras deficiências que infelizmente ainda existem em muitas escolas da zona rural multisseriadas (ou multiano). Verifica-se, em geral, uma atuação forte dos professores dessas escolas no intuito de diminuir quaisquer prejuízos no que se refere à compreensão dos conteúdos, à participação dos alunos nas aulas; se observa ainda uma ajuda mútua entre os sujeitos da comunidade escolar, ou seja, entre os professores, pais e alunos com características distintas conforme o contexto que atuam esses sujeitos.

A aproximação com essa temática e a escolha do meu objeto de pesquisa (a atuação sociopolítica do professor nessa escola) se deu a partir da realização de pesquisas, diagnósticos e estágios docentes ao longo dos Tempos Comunidades ${ }^{3}$ no percurso formativo propiciado pela alternância pedagógica no curso de Licenciatura Interdisciplinar em Educação do Campo da Universidade Federal do Pará, no qual

\footnotetext{
${ }^{3}$ Tempo Comunidade é uma atividade curricular obrigatória do curso de Licenciatura Interdisciplinar em Educação do Campo que ocorre no período entre etapa de aulas presenciais (Tempos Universidade), e consiste na realização de pesquisas nas comunidades de pertencimento dos estudantes deste curso, seminários nas escolas de educação básica e realização de intervenções socioeducativas por meio dos Estágios Docentes supervisionados.
}

ingressei como estudante em 2014, na turma de Linguagens e Códigos em Altamira.

No diálogo com algumas famílias de agricultores familiares e observando sua relação com a escola, percebemos que o professor é bem mais que isto nas comunidades, o professor acaba desenvolvendo em torno de si uma espécie de referência na comunidade, exercendo, em geral, uma liderança bastante significativa, buscando resolver problemas de cunho social por meio dos serviços na cidade, como: benefícios assistenciais junto ao Sindicato de Trabalhadores e Trabalhadoras Rurais, consecução de tratamentos de saúde, consertos de estradas, entre outros. Observamos ainda uma influência dessas relações, a partir de uma espécie de fortalecimento mútuo nem sempre explicitado nas falas, que reflete positivamente no processo de ensino e aprendizagem e no ambiente da escola.

Esses elementos empíricos acima descritos contribuíram para a escolha do objeto de pesquisa, bem como orientaram o olhar analítico sobre o mesmo.

A escolha do lócus da pesquisa que deu vida a este artigo (a escola rural multisseriada e distante da cidade, denominada Nossa Senhora da Conceição, localizada no km 135 Norte, em Medicilândia), bem como a escolha do professor Francisco (o professor Chico), principal sujeito desta pesquisa, deu-se a partir de informações obtidas junto a professores colegas de Chico e da própria Secretaria Municipal de Educação (SEMEC), os 
quais nos deram referências muito positivas sobre o trabalho docente do professor, considerando-se sua prática pedagógica e sua prática sociopolítica na comunidade.

Outro elemento influente da escolha dessa temática de estudo e desse perfil de professor, parte de minha experiência de vida quando adolescente, quando minha mãe cursou a Licenciatura em Pedagogia ofertada pela Universidade Federal do Pará (UFPA), o curso foi ofertado em Medicilândia a partir de uma parceria do governo municipal e a UFPA, e foi financiado pelo Fundo de Manutenção e Desenvolvimento do Ensino Fundamental e de Valorização do Magistério (FUNDEF), o qual ofertou a graduação para 40 professores que já atuavam em sala de aula, porém sem o ensino superior.

Algumas vezes minha mãe, a professora Janete, precisava me levar para as aulas, então, eu assistia as apresentações de alguns trabalhos dos demais professores e participava de algumas discussões em grupo. Foi nesse ambiente de troca de conhecimento que pude observar sobre como se dava a atuação do professor Chico e de outros professores que estudavam na mesma turma, todos atuantes nas escolas de educação básica no campo ou na cidade.

O professor Francisco é um dos professores mais antigos do município de Medicilândia, por isso, possui uma vasta experiência sobre o fazer docente. Neste artigo, então, analiso a atuação do professor como figura social, ou seja, alguém com ação e influência para além da sala de aula. Dessa for- ma, como objetivo, viso compreender a repercussão de sua atuação nas relações escolares (relação professoraluno-conhecimento) e nas relações extraescolares (participação da família na escola, processos de mobilização sócio-política e comunitário etc.). De forma específica, ao longo deste artigo, descrevo a trajetória do professor (sujeito da pesquisa); identifico e analiso as ações sociopolíticas do professor na comunidade.

O levantamento de dados para constituir este estudo se deu a partir da pesquisa qualitativa. Trata-se de um processo de compreensão (observação, interpretação e análise) de fatos e fenômenos sociais. $\mathrm{O}$ processo de compreensão se apresenta em dois níveis, o primeiro é o da compreensão direta sobre a ação humana sem apresentar quaisquer interferência do pensamento pessoal sobre os fatos, no segundo nível, e por vezes mais profundo, procura-se compreender a motivação da atividade e abstrair o significado que o indivíduo apresenta em sua ação (SANTOS FILHO, 2000).

A metodologia de pesquisa qualitativa é essencial para objeto de estudo em tela, pois viso descrever e analisar a atuação docente e as repercussões da mesma, a partir da busca dos significados que os sujeitos envoltos nessa atuação docente atribuem aos fatos, relações que a constituem. O estudo de caso é o método que melhor define a pesquisa realizada, uma vez que busca proporcionar vivências e reflexões acerca de um caso da vida real que tem um significativo papel social e político para determinado grupo (GODOY,1995). 
Para desenvolver esta análise, as técnicas para levantamento de dados utilizadas foram: entrevistas, observação no ambiente da escola, aplicação de questionários, entre outras.

\section{A escola e o professor Chico}

A pesquisa foi realizada na comunidade escolar e no ambiente comunitário extraescolar situado no $\mathrm{km} 135$ Norte a $30 \mathrm{~km}$ da faixa da $\mathrm{Br}$ 230, rodovia Transamazônica, com ênfase na atuação docente e sociopolítica do professor Francisco Severino dos Santos Filho (conhecido por Chico Picapau).

A referida escola atende alunos de séries diferentes em uma classe multisseriada com alunos do $2^{\mathrm{a}}, 3^{\mathrm{a}}, 4^{\mathrm{a}} \mathrm{e}$ $5^{\mathrm{a}}$ ano do ensino fundamental menor, totalizando 17 alunos, tendo somente o professor Chico para ministrar todas as disciplinas da chamada grade curricular.

As escolas que atendem turmas multiano são comuns na zona rural de Medicilândia, principalmente nas escolas que estão nas áreas mais distantes da cidade, atendendo a um número menor de alunos. Para Santos e Moura, esse modelo de educação ainda persiste desmistificando teses de que seja coisa do passado e assim caracteriza as classes multisseriadas (ou multiano):

O fenômeno das classes multisseriada ou unidocentes, são caracterizadas pela junção de alunos de diferentes níveis de aprendizagem (normalmente agrupadas em "série") em uma mesma classe, geralmente submetida à responsabilidade de um único professor. (SANTOS; MOURA, 2010, p.35)
Apesar do avanço na legislação educacional, que prevê a organização do ensino sem a seriação, essas escolas multiano seguem agrupando estudantes, mas dividindo-os por séries, os quais convivem cotidianamente nas salas de aula. A Lei de Diretrizes e Bases da Educação Nacional (LDB n ${ }^{\circ}$ 9.394, de 20 de dezembro de 1996) regulamenta o funcionamento da educação básica da seguinte forma:

\footnotetext{
Art. 23. A educação básica poderá organizar-se em séries anuais, períodos semestrais, ciclos, alternância regular de períodos de estudos, grupos não seriados, com base na idade, na competência e em outros critérios, ou por forma diversa de organização, sempre que o interesse do processo de aprendizagem assim o recomendar (BRASIL. Lei de Diretrizes e Bases da Educação Nacional. 1996, p. 17)
}

Ao observar a aula do professor Chico, percebo que, mesmo dentre as inúmeras dificuldades enfrentadas para assumir o comando de várias series, e de diferentes níveis de aprendizagem, o professor assume uma postura de tranquilidade e de coordenação da turma como um todo, sem distinção entre as séries; promovendo uma integração que se fortalece na troca de conhecimento entre os alunos ao adotar uma organização pedagógica própria para dar conta das especificidades encontradas em sua turma composta por séries distintas.

O professor Francisco exerce múltiplas funções na escola como: professor, diretor, orientador educacional, zelador e, por muito tempo, foi também cozinheiro, entre outras fun- 
ções extraescolares. Assim ele se refere quanto à dificuldade de ser professor nessas condições adversas de trabalho: "Como é que você vai dar aula e cuidar de uma panela?" (trecho de entrevista cedida em 04/09/2017).

Professor Chico tem 41 anos, é casado e reside no km 135 desde 1994 onde se localiza a escola lócus desta pesquisa. Formou-se em pedagogia pela Universidade Federal do Pará (UFPA), concluiu o curso em 2008, é pós-graduado em psicopedagogia por uma universidade particular, concluída em 2010. Quando chegou na vicinal para atuar como professor, foi lotado na escola de sua comunidade chamada de Escola Municipal de Ensino Fundamental Maravilha, onde reside desde então. Atuou nessa escola até 2007. Após esse ano, a escola foi fechada, pois não tinha número suficiente de alunos para formar turma. Como nesse mesmo ano a escola Nossa Senhora da Conceição estava passando por dificuldades com relação à permanência de professor na comunidade, geralmente vinha um professor e desistia e depois vinha outro, então a comunidade o chamou para lecionar na Escola Nossa Senhora da Conceição que se situa a $11 \mathrm{~km}$ de sua propriedade.

Para uma boa atuação profissional do professor, sabe-se que este precisa munir-se de conhecimentos por meio das teorias de ensino e aprendizagem, “[...] mas sempre será necessário que o professor conheça a realidade de vida do seu aluno, sua classe social suas experiências de vida, suas dificuldades, a realidade de sua família etc." (BOCK, et al, 2001, p.157). Parte da experiência positiva do professor
Chico na condução do ensino na escola do campo, advém dessa posição do professor de se colocar na relação de diálogo com os sujeitos envolvidos em seu trabalho docente.

\section{O caminho da escola, a rotina escolar} do professor Chico e seus alunos

Cheguei na escola Nossa Senhora da Conceição e me deparei com um estacionamento de motos em frente à escola, e logo pensei qual seria a idade dos alunos que encontraria na sala de aula, ou seja, jovens e adultos com habilitação para dirigir veículos. Ledo engano! Os alunos eram jovens adolescentes, tinham de 11 a 13 anos. $\mathrm{Eu}$ me aproximei e logo visualizei o professor Chico sentado na porta da sala, ele estava no momento de correção de atividade escrita da disciplina de Ciências. Os alunos vinham até ele e individualmente ele corrigia as atividades e dirigia a eles um feedback. Aproximei-me e cumprimentei o professor que logo se levantou e, de forma bem alegre - como sempre se porta em suas aulas -, saudou-me com as boasvindas.

Apesar de se tratar de uma turma de multiano ou multissérie, as aulas são compartilhadas sem direcionar a um ou a outro grupo de alunos conforme a série, assim o professor expõe que, às vezes, faz uma pergunta para um aluno do $4^{\mathrm{a}}$ ano e, espontaneamente, um aluno do $2^{\mathrm{a}}$ ano responde, tornando a aula participativa para todos, respeitando-se os níveis distintos de apreensão ou interpretação dos conteúdos. 
Após a correção das atividades, o professor liberou os alunos para o intervalo. Neste dia, não tinha lanche, pois a escola esteve sem alimentos disponíveis para os alunos. Naquele momento, o professor Chico até brinca com esse fato e diz: "Hoje os gordinhos vão fazer regime e os magrinhos vão dar um apoio moral para o regime dos demais", todos riem e, em seguida, são liberados para o intervalo. No intervalo, o professor Francisco me informou que naquela semana ele esteve realizando uma revisão de assuntos da disciplina de Ciências e que naquele dia estava aplicando uma sequência de exercícios, em que o professor copiava os exercícios no quadro e pedia para que os alunos respondessem. Para alguns professores, esse fato pode causar estranheza por pensar no cansaço típico de uma sequência de exercícios, entretanto, ele consegue conduzir de uma forma divertida e partilhada, e não mecânica ou monótona, o que revela a criatividade e habilidade pedagógica do professor, as quais agradam a comunidade escolar e extraescolar.

Em entrevista ${ }^{4}$ realizada com duas alunas do professor Chico, elas expõem que "o professor Chico nos ensina muito bem" (Daiane. Estudante). Yasmim reafirma as informações de Daiane: "O professor Chico nos ensina muito bem, eu gosto muito de matemática, mas as outras matérias são bem interessantes e aprendemos bastante com o professor". Em face de relevantes falas das alunas acima citadas, observamos que o método utilizado pelo professor Chico surte um efei-

${ }^{4}$ As entrevistas das alunas foram realizadas no dia 28/11/2017. to positivo na compreensão dos conteúdos. O grande educador Paulo Freire expõe a importância da "rigorosidade metódica" quando utilizada para despertar no educando uma consciência crítica do objeto a ser estudado:

\footnotetext{
O educador democrático não pode negar-se o dever de, na sua prática docente, reforçar a capacidade crítica do educando, sua curiosidade, sua insubmissão. Uma de suas tarefas primordiais é trabalhar com os educandos a rigorosidade metódica com que devem se "aproximar" dos objetos cognoscíveis. E esta rigorosidade metódica não tem nada que ver com o discurso "bancário" meramente transferidor do perfil do objeto ou do conteúdo. É exatamente neste sentido que ensinar não se esgota no "tratamento" do objeto ou do conteúdo, superficialmente feito, mas se alonga à produção das condições em que aprender criticamente é possível (FREIRE, 1996, p.2829).
}

Partindo da reflexão que Freire nos traz acima e observando a aula do professor Chico, o qual lança mão de sessões de exercícios (que outrora pode se identificar como um método tradicional de ensino), observamos que, mesmo tendo rigorosidade metódica para estabelecer critérios de aprendizagem e para conduzir as aulas, em sua classe, prevalece um ambiente de dialogicidade entre os conteúdos abordados e a vida dos educandos, usando exemplos de objetos comuns ao dia a dia dos alunos. Propiciando sempre condições para o aprendizado crítico de determinado objeto de estudo, o professor se posiciona não como transferidor de conhecimento, mas como quem cria estratégias que ajudam os 
alunos a pensar sobre determinado assunto (FREIRE, 1996). Observa-se ainda nessa prática o uso de pontos de ancoragem como motivação para o novo aprendizado; segundo a teoria de David Ausubel, estes consistem em conceitos, informações que os sujeitos já possuem e servem de mediadores entre este saber prévio e/ou empírico e as novas informações e conceitos (BOCK, 2001).

Observamos que a prática de ensino do professor Chico se baseia em pedagogias ativas e construtivistas, inspiradas nas ideias educacionais de Dewey e Paulo. Segundo Ghiraldelli, essa forma de ensinar

[m]ais do que a conclusão de cada lição do processo de ensinoaprendizagem, o que valeria a pena, é que ele estaria treinando os indivíduos para a pesquisa, para o que seria o trabalho natural da mente resolver problemas novos. (GHIRALDELLI, 2002, p.46)

Entendemos acerca dos apontamentos trazidos pelo teórico que "não basta só aprender, mas é necessário aprender a aprender" (GHIRALDELLI, 2002, p.46), ou seja, ter autonomia para questionar o que não se sabe e construir o conhecimento. As concepções de ensino defendidas por Freire aproximam-se em parte na concepção ativa de ensino de Dewey. Freire acrescenta a esta importantes reflexões sobre o envolvimento dos seres em sala de aula enquanto humanos, defende a importância do relacionamento de amor, refletido na relação dialógica, que precisa existir nesse ambiente, e ressalta a importância da comunidade como centro nessa relação fortalecida no convívio em sala de aula. Ambos os autores concebem elementos em suas teorias presentes na prática do professor Chico. Mesmo com a prática de promoção de resolução de exercícios pelos alunos em suas aulas, o professor se posiciona como agente articulador e promove o processo de reflexão sobre os assuntos, instigando a curiosidade, a pesquisa, construindo junto o caminho para o conhecimento.

No momento dos exercícios, observa-se uma troca importante de conhecimento, em que os alunos se ajudam e dialogam entre si; entre uma ajuda e outra, acontece uma brincadeira, uma piada entre os alunos e o professor e o ambiente continua sendo de alegria e de troca. A rotina diária das aulas na escola assume sempre essa forma, que parece ser a cultura escolar impressa pelo professor e os alunos no encontro diário.

O espaço da escola é utilizado pelos sujeitos como um lugar de interação que denota uma convivência propícia ao desenvolvimento, o professor se apresenta como um agente que conduz esse processo de interação. Vigotski reflete sobre esse fenômeno trazendo-o como elemento principal para a criação das zonas de desenvolvimento proximal que consiste na:

[...] distância entre o nível de desenvolvimento real, que se costuma determinar através da solução independente de problemas pela criança, e o nível de desenvolvimento potencial, determinado pela solução de problemas sob a orientação de um adulto ou em colaboração com companheiros. (BOCK, et al, 2001, p.46) 
As zonas de desenvolvimento proximal se desenvolvem pela interação entre os indivíduos que se relacionam em um determinado espaço com níveis distintos de apropriação do conhecimento e habilidades escolares, e é exatamente na diferença de aprendizados que a classe multiano pode propiciar essa forma de construção de conhecimentos, porque não se avalia como unicamente importantes as habilidades inatas ou as que os alunos já dominam, mas o que estes podem vir a desenvolver sob a mediação da cultura representado pelos pares mais experientes, uma vez que para Vigotski, "o desenvolvimento é um processo que se dá de fora para dentro. É no processo de ensino-aprendizagem que ocorre a apropriação da cultura e o consequente desenvolvimento do indivíduo" (BOCK, et al, 2001, p.162).

Ao final da aula, o professor agradece a minha presença e se despede de todos, então, nos dirigimos até a área externa para a despedida com os alunos. Todos se cumprimentam e se deslocam para os seus meios de transporte. A escola não conta com transporte escolar, os chamados "carros de alunos", então, os alunos se deslocam para a escola a pé, ou em motocicletas; crianças de 11 anos já têm habilidades e desenvoltura com a condução de motocicletas. No caminho para a escola (como já sinalizado em outro trecho deste artigo), os alunos se deparam com alguns obstáculos como: areal, pontes perigosas e estradas esburacadas, tendo ainda que transportar outras crianças em suas motocicletas; por alguns trechos se faz necessário dar carona para alguns colegas, eles trans- portam em média de dois a três colegas na garupa de suas motos.

Fico bastante estarrecida com tal situação, mas observo que eles conduzem muito bem o veículo, me deixando ainda mais abismada, mas tranquila com a certeza de que cada um leva consigo a satisfação de estar mais um dia participando da aula do professor Chico.

Um sentimento que percebo na observação e entrevistas que realizei: os alunos expressam satisfação na interação que se reflete na desenvoltura e no envolvimento da turma no ambiente de sala de aula.

Acompanhei os dois alunos que havia entrevistado até suas casas e aproveitei para realizar entrevistas com suas famílias, as indagações foram referentes ao papel que o professor Francisco exerce na escola, tanto como professor, quanto como uma espécie de mediador entre campo e cidade na busca de desenvolvimento local. Os pais disseram em suas entrevistas que acreditam no potencial do professor Chico: "A minha filha começou a frequentar a escola [onde o professor Chico dar aula] com 5 anos [...], quando ela passou pro primeiro ano, ela já sabia ler" (Bruna, mãe de estudante. Entrevista realizada em 28/11/2017). A senhora Bruna expõe ainda que seus filhos demonstram aprender de forma efetiva com o professor Chico: "O professor Chico é um bom professor, os meus meninos aprendem muito com ele" (Entrevista cedida dia 28/11/2017).

Além das habilidades didáticas e pedagógicas, os pais destacam qualidades positivas do professor quanto à 
sociabilidade junto às famílias, pois, ao acompanharem o desenvolvimento dos seus filhos na escola, observam a qualidade do ensino que é transmitido, dizem que o professor é um integrante bem antigo da comunidade e que tem muita participação nas decisões sendo interativo no convívio em comunidade e com as famílias.

\section{Significados de ser professor do campo}

O professor Chico expõe que gosta de viver na zona rural devido a vários aspectos: "Além da paixão por estudar e dar aulas, eu sou apaixonado pelo campo (...), a relação com a natureza, a alimentação, a paz, o clima; moramos na beira do rio com uma agua maravilhosa, então eu sou apaixonado pelo campo" (entrevista cedida dia 04/09/2017). Outro aspecto que o motiva a exercer esse papel profissional no campo é o companheirismo entre as pessoas. Professor Francisco diz que no campo todos se conhecem e se cumprimentam demonstrando um sentimento de companheirismo, diferente do ambiente urbano onde as pessoas não se falam, nem tão pouco se dispõe a conhecer umas às outras devido à violência que existe na zona urbana.

Observa-se, então, um sentimento de pertencimento ao campo e aos sujeitos que vivem nesse espaço. Essa característica, certamente, propicia a relação de diálogo entre Chico e as famílias de seus alunos, a convivência mais próxima entre eles e mais propícia a um olhar sensível e informado sobre as relações sociais no campo, o tipo de sociabilidade tradicional e, é claro, esses elementos o capacitam a desenvolver um saber e um modos operante diferenciados. Tais elementos parecem construir uma identidade docente próxima à ideia de sacerdócio, dada a dedicação e a entrega do professor ao ensino e à comunidade da qual a escola faz parte.

Antes do processo de profissionalização da profissão docente no Brasil do século XX, o magistério era visto como expressão de sacerdócio. $\mathrm{O}$ professor era um líder que trabalhava no magistério, mas que o fazia como expressão de uma missão proferida pelo seu ímpeto de agente social na comunidade e dedicação a ela. Kreutz assim define essa atuação da seguinte forma:

Sua ação educativa na escola deveria ter vinculação com a ação educativa na comunidade, tornando-se localmente o agente principal dessa orquestração educativa, vinculando escola e comunidade. Daí o realce para as funções extra-escolares. Posto como o guardião da ordem estabelecida competia-lhe assegurála não somente pelo ensino, mas especialmente pelo seu exemplo de vida e pela sua incansável atuação no campo religioso e social. Daí a concepção do magistério e suas extensões de serviço social como uma vocação, um sacerdócio, uma missão. (KREUTZ, 1986, p.14, apud HIPÓLITO, 1997, p.21)

Nas reflexões que o autor traz, destacamos a importância desse fazer docente vinculado ao convívio comunitário tendo em vista que, nesse processo, o professor é partícipe de uma vida social que se entrelaça no seu 
fazer docente. Com o processo de profissionalização ou funcionarização da profissão docente pelo Estado, a figura do professor se distancia de suas funções comunitárias e sociais; e o próprio professor se distancia do controle que tinha sobre seu trabalho; também é reduzido o seu prestígio social (HIPÓLITO, 1997, p.21).

Ao indagá-lo sobre a importância de ser um professor, ele expõe que a escola, além de ensinar o aluno para ter uma profissão, precisa ensinar para a vida, para o convívio em sociedade e, sobre isso, reflete Paulo Freire: "Seria uma contradição se amoroso, humilde e cheio de fé, o diálogo não provocasse este clima de confiança entre os sujeitos" (FREIRE, 1968, p.21). O processo de ensino e aprendizagem precisa ser propício à troca e ao encontro entre os homens que buscam mais, não se esgotando ao mero transferir conhecimento, mas construir conhecimento, pois "[a] educação autêntica, repitamos, não se faz de $A$ para $B$ ou de A sobre B, mas de A com B, mediatizados com o mundo" (FREIRE,1968, p.84).

O mestre Paulo Freire ainda nos mostra a importância da educação como instrumento de intervenção no mundo, que dignifica ainda mais o fazer pedagógico, pois, tal como ressaltou anteriormente o professor Chico em entrevista aqui já exposta, procura intervir socialmente para preparar o aluno para vida:

Outro saber de que não posso duvidar um momento sequer na minha prática educativo-crítica é o de que, como experiência especificamente humana, a educação é uma forma de intervenção no mundo. Intervenção que além do conhecimento dos conteúdos bem ou mal ensinado e/ou aprendidos implica tanto o esforço de reprodução da ideologia dominante quanto o seu desmascaramento. (FREIRE, 1997, p.110)

Outro elemento definidor do significado do magistério para o professor Chico, é uma preocupação política (ainda que ele não defina assim) com o campo e sua reprodução. Ressalta sempre em suas aulas a importância da permanência das famílias no campo, aconselha seus alunos sobre a importância de "estudar mais para continuar no campo e não para se tornar mão de obra dos comércios na cidade". Tal discurso denota uma postura distinta da maioria dos docentes no campo e na cidade, tal como os que observei nas pesquisas dos Tempos Comunidades, para os quais o campo seria o lugar do atraso, e o estudo a libertação deste lugar, o passaporte para a cidade como ideal de vida.

A postura do professor Chico e suas representações sobre a relação estudo/escola e campo revelam elementos do conceito político de Educação do Campo, a qual nasce da luta dos Movimentos Sociais ligados ao campo que buscam afirmar a importância de uma educação pública do campo pensada e implantada a partir da realidade camponesa (CALDART, 2012, p.259). Os sujeitos do campo precisam se sentir parte dessa construção e, para tanto, é necessário valorizar a vida no campo e respeitar de forma a educar os alunos para se posicionarem frente a defesa do seu modo de vida, da importância da agricultura 
familiar para a economia, educação, soberania e segurança alimentar dentre outros fatores que crescem a partir da permanência das famílias em seus territórios.

Observo que o professor Francisco faz do ambiente de sociabilidade em sala de aula um espaço de troca. Troca de sentimentos, troca de experiências e de aprendizados, o que dignifica seu trabalho e demonstra que o "[...] fazer docente é feito com entrega e transparência (FREIRE, 1996, p.80).

A dialogicidade política e pedagógica da atuação docente do professor Chico é assim revelada nas falas a seguir:

A gente se respeita muito na aula do professor Chico" (Yasmim, aluna. Entrevista realizada no dia 28/11/2017).

Eu me considero muito esforçado na minha atuação, não é qualquer problema que me faz faltar nas aulas, e quando preciso sair dialogo antes com os alunos e suas famílias e reponho o tempo em algum feriado (Professor Chico. Entrevista realizada no dia 04/09/2017).

\section{O fazer docente do professor e sua atuação sociopolítica}

Professor Francisco expõe que, em suas aulas, procura discutir não somente o conteúdo programático da grade curricular, mas também temas pertinentes que estão sendo discutidos na sociedade (seja no ambiente familiar ou nos demais espaços, meios de comunicação, etc). Assim se expressa o professor Francisco: "Os meninos são o espelho de casa, o que eles ouvem em casa, eles transmitem na esco- la e eu aproveito para discutir sobre esses temas trazidos pelos alunos". Valorizar o saber familiar e das experiências adquiridas pelas vivências como instrumento para nortear o fazer docente, é algo imprescindível para implantar uma educação que seja própria do campo:

Precisamos aprender a potencializar os elementos presentes nas diversas experiências e transformá-los em um movimento consciente de construção das escolas do campo como escolas que ajudam neste processo mais amplo de humanização e de reafirmação dos povos do campo como sujeitos de seu próprio destino, de sua própria história. (ARROYO; CALDART et al, 2009, p.89)

O conceito de educação do campo passa pela importância de partilhar o conhecimento de uma forma aberta e crítica, em que possa haver o diálogo não somente sobre os conteúdos, mas também sobre as questões sociais trazidas para o ambiente de sala de aula e extraclasse.

O professor Chico revela um forte pertencimento à sala de aula, à escola e uma preocupação política com a comunidade. Assim, procura estar sempre presente na escola. Quando precisa faltar para participar de eventos da igreja, dialoga com os pais e alunos e compensa esses dias nos feriados, procurando ser pontual em suas aulas. Expõe que a escola para ele não é só um ambiente de dar aulas e seguir o conteúdo programático; é também um espaço de conscientização para a vida em sociedade, diz que sempre procura aconselhar seus alunos sobre 
problemas de cunho social como: alcoolismo, o uso de drogas, a violência. Sente-se muito incomodado quando um aluno "seu se desvia por tais caminhos". Paulo Freire em sua obra Pedagogia da Autonomia nos mostra essa figura do professor que é também educador, pois seu ato de ensinar visa proporcionar “[...] capacidade de aprender, não apenas para nos adaptar mas sobretudo para transformar a realidade, para nela intervir, recriando-a" (FREIRE, 1996, p.76).

Observar a aula do professor Francisco foi bem importante para validar informações previamente obtidas através das entrevistas, nas quais destacam-se os seguintes adjetivos ou expressões adjetivas sobre sua atuação docente: companheiro, amigo, orientador, conselheiro, dinâmico, respeitoso, criativo, extrovertido, prestativo, religioso, participativo, presente. Em sala de aula, ele é carinhosamente chamado de Chico, e trata os alunos de forma bem informal, de brother, amigo, colega, o que imprime ao espaço de sala de aula um ambiente de companheirismo, porém sem perder a liderança pedagógica na condução da disciplina e do aprendizado, e nem o respeito dos alunos. Se observa então uma relação de confiança, entre pares no ambiente de sala de aula, uma relação de iguais com posições e papéis distintos, mas não hierárquicos. Talvez esta atuação docente seja uma expressão concreta do que Freire define como relação dialógica.

$\mathrm{Na}$ reunião de pais, o professor expõe o seu planejamento para todo o ano, então os pais ficam inteirados de todo o percurso escolar dos filhos.
Percebe-se que há uma partilha do que é pensado para as aulas, com a comunidade escolar; que há um planejamento em conjunto. $\mathrm{O}$ professor informa que nas reuniões, apesar de poucas, raramente há a falta de algum pai ou mãe, e que a participação ativa deles nessas ocasiões é um fato.

Há também atuações para a implementação de serviços públicos na comunidade. Outro problema persistente na escola é com relação a oferta do ensino fundamental maior. A prefeitura esteve relutante em não abrir uma turma do sistema de oferta de ensino via Modular Rural na escol, assim, em parceria com a comunidade, professor e famílias realizaram um mutirão e conseguiram construir uma sala na escola Nossa Senhora da Conceição para que os alunos continuassem tendo a oferta das aulas, entretanto a SEMED está constantemente ameaçando interromper as aulas dessa turma que está estudando a custo de reinvindicações do professor e comunidade.

Para além de ser um articulador na defesa de questões sociais na comunidade, o professor realiza diálogos importantes sobre tais questões com os alunos e com as famílias no decorrer do seu trabalho como podemos detectar nas entrevistas. Ao enfatizar problemas de cunho social, o professor Chico levanta questões e promove diálogos propícios ao desenvolvimento do saber crítico que o educando precisa construir em contato com o conhecimento. $\mathrm{O}$ escritor Henry Giroux reflete sobre esse papel politizador que o professor precisa assumir no exercício do magistério assumindo-se como in- 
telectual transformador, papel contrário ao exercício docente meramente tecnicista que se vincula de forma mecânica com o conhecimento (GIROUX, 1997, p.159).

A práxis reflexiva precisa ser constante no ambiente escolar, o educando precisa se sentir parte integrante do todo que é a escola, para tal efeito o professor precisa ser o protagonista da sua ação e não meramente instrutor do conhecimento, pois, ao se pôr como protagonista, ele se torna também uma referência para a comunidade escolar pelo seu fazer docente autônomo, passível de reflexão pela comunidade.

Esta atenção ao ensino de qualidade no/do campo é revelada também por meio das observações realizadas por mim em sala de aula e entrevistas. O professor avalia o ensino ofertado na zona rural e expõe que o estereótipo lançado de que a educação ofertada no campo não é de qualidade, é uma farsa, uma enganação; ele analisa que "[...]o que acontece, é que o governo municipal não se preocupa com as habilidades do profissional que são contratados para dar aula no campo"; critica ainda o fato de "[...] contratarem o profissional para uma determinada escola e antes desse profissional criar laços nessa escola, já o lota em outra escola então não se fortalece um vínculo com a comunidade", o que é muito importante para o processo de ensino e aprendizagem.

\section{Considerações finais}

No decorrer da pesquisa aqui apresentada, podemos visualizar a importância da prática docente do profes- sor do campo, o Chico, que se mostra digna de conhecimento pela comunidade acadêmica dada suas características formativas. A prática pedagógica aqui abordada em especial nos traz um fazer docente efetivo do campo que respeita as características e as peculiaridades da vida neste território que se fortalece por meio do papel socioeducativo e político exercido pelo professor Chico.

O grande mestre Paulo Freire nos mostra um horizonte de princípios éticos, pedagógicos e políticos que se refletem na prática do professor Chico, cujo fundamento de ensino se assenta em muitos aspectos na forma construtiva de educação escolar. Há ainda a parceria construída com a comunidade escolar e extraescolar revelando a prática educadora que se faz não somente pelo papel de professor em sala de aula, mas pela mediação entre alunosfamílias-sociedade. A essência de suas aulas se constrói a partir da ligação entre vida e educação que transmite aos alunos um fazer próprio e pertencente a sua vida e ao seu convívio, essa prática fortalece a identidade dos povos do campo ao qual ele atende, com os quais ele convive, isto torna visível a contribuição que esse docente trás para que não ocorra o êxodo rural e a evasão escolar.

A Educação do Campo se constrói a partir do protagonismo das comunidades rurais, estas são propulsoras das diretrizes que norteiam a ação pedagógica da instituição escolar. $\mathrm{O}$ professor Chico se aproxima muito dessa concepção transformadora que a educação precisa assumir junto às famílias, e o faz apesar das (por vezes 
superando) desigualdades sociais, da falta de recursos e de investimento municipal; entretanto ao invés de ficar se lastimando das dificuldades, ele constrói mecanismos para trazer ao centro o que é importante para a educação: o fazer pedagógico com entrega e com diálogo.

Em meio a tanto descaso com a educação pública do campo, ainda há esperança, pois, como dizia o grande
Educar Paulo Freire: "É preciso ter esperança. Mas tem de ser esperança o verbo esperançar", ou seja, essa esperança precisa ser instigadora, transformadora é necessário "correr atrás", e essa lição do grande educador eu constatei na prática docente do professor Chico e vou levar comigo, na minha prática como mãe, educadora, sindicalista e universitária. 


\section{Referências}

ARROYO, Miguel Gonzalez; CALDART, Roseli Salete; MOLINA, Mônica Castagna (org.). Por uma Educação do Campo. 4 ed. Petrópolis, RJ: VOZES, 2009.

BOCK, Ana Mercés, et al. Psicologias: uma introdução ao estudo de psicologia. São Paulo: Saraiva, 2001.

BRASIL. Lei de Diretrizes e Bases da Educação Nacional. 1996.

CALDART, Roseli Salete (org); PEREIRA, Izabel Brasil; et.al. Dicionário da Educação do Campo. Rio de Janeiro, São Paulo: Expressão Popular, 2012.

FREIRE, Paulo. Pedagogia da Autonomia: saberes necessários à prática educativa. São Paulo: Paz e Terra, 1996 (Coleção Leitura).

Pedagogia do Oprimido. São Paulo: Paz e Terra, 1968.

GIROUX, Henry. Os Professores como Intelectuais. Rumo a uma pedagogia Crítica da Aprendizagem. Porto Alegre: Artes Médicas,1997.

GODOY, Arilda Schimidt. Revista de Administração de Empresas. São Paulo: EAESP / FGV, 1995.

HYPOLITO, Álvaro Moreira. Trabalho Docente, Classe Social e Relações de Gênero. Campinas: São Paulo, 1997.

ROCHA, Maria Isabel, HAGE, Salomão Mufarrej (organizadores). Escola de Direitos: reinventando a escola multisseriada. Belo Horizonte: Autêntica Editora, 2010 (Coleção Caminhos da Educação; 2).

SANTOS FILHO, José Camilo dos; GAMBOA, Silvio Sánches (org.). Pesquisa Educacional: quantidade-qualidade. $3^{\mathrm{a}}$ ed. São Paulo: Cortez, 2000 (Coleção Questões da Nossa Época: v. 42).

$O(s)$ autor $(e s)$ se responsabiliza(m) pelo conteúdo e opiniões expressos no presente artigo, além disso declara(m) que a pesquisa é original.

Recebido em 19/03/2020

Aprovado em 04/03/2020 